\title{
INTRODUCTION
}

\section{ENVIRONMENTALLY INDUCED DisPlaCEMENT AND ForCED MigRATION}

\author{
Pablo Bose and Elizabeth Lunstrum
}

$\mathrm{D}$ isappearing coastlines, fields and homes flooded by rising waters, lands left cracked and barren by desertification, a snowpack shrinking in circumpolar regions year by year-these are only a few of the iconic images of climate change that have evoked discussion, debate, and consternation within communities both global and local. Equally alarming has been the threat of what such degraded and destroyed landscapes might mean for those who depend upon them for their livelihoods-as their homes, as their means of sustenance, and as an integral part of their cultural and social lives. A mass of humanity on the move-some suggest 50 million, 150 million, perhaps even a billion people ${ }^{1}$-the spectre of those forced to flee not as the result of war or conflict but rather a changed environment haunts the imaginaries of national governments, international institutions, and public discourse alike. Are these environmental refugees? Should they be granted the same protections and support as those who can prove their fear of and flight from persecution? Do the sheer numbers contemplated by the scale of the events and factors threaten to overwhelm the international refugee system?

Moreover, the effect of an altered climate is but one of the drivers of what might be termed "environmentally induced displacement" (EID). Extractive industries-oil, gas, minerals, and lumber among them-have left scarred and despoiled lands in their wake. ${ }^{2}$ Collapsing fisheries and livestock herds bring their own forms of environmental disruption to the lives of those who depend upon them. Conservation initiatives meant to protect such resources and biodiversity alike have often resulted in the displacement of those already living in such zones or in restrictions on their ability to access or use their lands. ${ }^{3}$ Development too is a contributor to EID, from increased urbanization to megaprojects like dams, highways, and railroads. ${ }^{4}$ Added to these "human-made" processes are the effects of "natural disasters," including hurricanes, earthquakes, floods, and tornadoes that have swept people from their homes in a series of well-publicized events in recent years.

These processes disproportionately affect marginalized groups within their respective contexts-indigenous communities, the poor, and women. Many of the most affected groups are often vulnerable to begin with, lacking secure rights and access to resources and to formal recourse once these are jeopardized. Despite this apparent lack of power, the subjects of EID have consistently organized to contest their dislocation-often in highly visible ways, as in global protests against dams, oil development, and parks creation can attest. ${ }^{5}$ Yet even with such notoriety, EID has not abated in recent years; if anything, the scale of extraction, the expansion of conservation zones, and the threat of climate change and what to do about it has only served to intensify processes of environmental displacement. ${ }^{6}$

In this special issue of Refuge we explore the phenomenon of EID through both conceptual and empirical work. We are interested in several key questions: What constitutes environmental displacement? How have various local and international actors responded to environmentally induced displacement? What are some of the debates regarding the concept of environmental refugees and their place within the international protection system? Additionally, the complexity of EID demands that we engage with the practices and discourses that help to organize and rationalize displacement. In this introduction we begin by briefly outlining some of the key literature on EID with a particular emphasis on environmental refugees. We focus as well on the overlaps and distinctions between conflict-induced, developmental, and environmental refugees. We are interested in the spatial dimensions of these processes-especially in 
terms of concepts such as repatriation and non-physical displacements. We then turn to a brief discussion of the way in which the contributors to this special issue advance our understanding of EID by illustrating its complexities, the various scales at which these processes operate, the diverse perspectives of key stakeholders, and the impact upon displacers and displaced alike.

\section{Environmental Refugees?}

Since at least the 1980s, the topic of environmental refugees more generally and of climate-induced migration more specifically has been a controversial one amongst international organizations, nation states, and local movements alike. Among the debates are definitional questions: How many people might be displaced and by what specific events/processes? Is the term refugee, with all that it connotes and implies and the systems of protection it might suggest, an appropriate one to use? To some extent these controversies extend far beyond the use of the label refugee to the contestation of climate science and global environmental politics. Amongst those who do agree that climate change-no matter what its causes-exists, there remains a great deal of disagreement as to what it portends. Gemenne suggests that there is a divide amongst those concerned with the issue of EID between "alarmists" who speak of high displacement estimates and broad and sometimes stark definitions of "environmental refugees" and "skeptics" who favour much more modest displacement figures and more nuanced and multi-causal factors as the drivers. ${ }^{7}$

One of the best-known proponents of the "alarmist" school is Myers, who in 1997 estimated that there were "at least 25 million environmental refugees ... a total to be compared with 22 million refugees of the traditional kind." 8 At the time he predicted that by 2025 over 200 million people would be displaced worldwide as a result of the impacts of a changing climate, with greater numbers by mid-century, and in his ongoing public lectures and scholarship on the subject his figures have ranged even higher. Such claims have become common both within the academy and without-some have even argued that as many as a billion people might eventually be displaced by climate change. ${ }^{9}$ Other scholars have been critical of such claims, however, finding them based on little to no empirical evidence, poor modelling, or exaggerations. ${ }^{10}$ Such "skeptics" have urged the adoption of more critical perspectives so as to avoid allowing such misperceptions to spread.

These figures remain prominent in the public's imagination, however; their size may be due to the wide range proposed by some of the first scholars to use the term environmental refugees, such as El-Hinnawi who defined them as "people who have been forced to leave their traditional habitat, temporarily or permanently, because of a marked environmental disruption (i.e., any physical, chemical and/ or biological changes in the ecosystem or resource base that render it ... unsuitable to support human life) ... that jeopardized their existence and/or seriously affected their quality of life."11

Others, such as Suhrke and Visentin, have criticized El-Hinnawi's definition for being "so wide as to render the concept virtually meaningless ... Uncritical definitions and inflated numbers lead to inappropriate solutions and compassion fatigue. We should not, however, reject outright the concept of environmental refugees. Instead we should formulate a definition that is more narrow but precise." 12

Other scholars, such as Richmond ${ }^{13}$ and McGregor, ${ }^{14}$ have argued that the conceptualization of environmental refugees must acknowledge the environmental factors and the social, economic, political, cultural, and technological factors that influence environmental migrations. Within the global refugee regime, the term environmental refugee has also sparked considerable debate, primarily regarding the legal application of the concept. For example, the UNHCR has stated that it "has serious reservations with respect to the terminology and notion of environmental refugees or climate refugees. These terms have no basis in international law ... UNHCR is actually of the opinion that use of such terminology could potentially undermine the international legal regime for the protection of refugees whose rights and obligations are quite clearly defined and understood ... UNHCR considers that any initiative to modify this definition would risk a renegotiation of the 1951 Refugee Convention, which would not be justified by actual needs." 15

The politics of environmental refugees-their definition, their production, their legitimacy, the determination of who might be responsible both for and to them-remains deeply contentious. Some small island nations have threatened lawsuits in the International Criminal Court against industrialized nations, ${ }^{16}$ while other countries refuse to accept the category as a basis for providing sanctuary, ${ }^{17}$ and the increasing frequency of "natural" disasters has raised the stakes for what to do with the subjects of environmental hazard. ${ }^{18}$ It is to this burgeoning field of scholarship, political debate, and advocacy/activism that many of the articles in this special issue contribute.

\section{Environment, Conflict, Development, and Displacement}

The articles in this special issue also draw attention to the limitations of a global refugee regime that recognizes the legitimacy primarily of those who have been displaced by a conflict or persecution on the basis of race, religion, 
nationality, ethnicity, or political ideology. It is clear that increasing attention over the past half-century has been paid to the fact that forced migration is and has been caused by many factors beyond armed conflict, including those tied to environmental factors and development projects. In many cases the drivers of such displacements may be overlapping, as with "resource wars" or resistance movements against particular forms of large-scale development. ${ }^{19}$ Whatever the reasons for dislocation, the outcomes are nonetheless often quite similar: homelessness, landlessness, the loss of livelihoods and connection to important cultural and/or religious spaces, and in many cases physical and mental harm. ${ }^{20}$ Yet the apparatus for global refugee protection tends to prioritize some factors-conflict and persecution based on political and religious beliefs as well as some identities-over others (such as development or environment). The constraints of such a definition have been tested in recent decades by new instances of conflict that are distinct from the post-Second World War context in which the structures of global refugee protection are based. The preponderance of forced migration within rather than across borders has given rise to the category of internally displaced persons (IDPs), while protracted situations, the role of non-state actors, and the context of global geopolitics have meant a radical re-examination of ideas such as repatriation and non-refoulement. ${ }^{21}$ The UNHCR's Guiding Principles on Internal Displacement does explicitly include the effects of development projects and natural or human-made disasters as amongst the drivers of forced migration within borders; however, the principles remain dominated primarily by a focus on conflict. ${ }^{22}$ In addition, official refugee status has not been granted on explicit environmental grounds or those tied to development-induced displacement.

Some might suggest that to address all the forms of displacement in the world would be to overwhelm the current system, given the sheer numbers involved and the complexities in determining causality. Yet this remains an unsatisfactory answer: if forced migration constitutes a violation of human rights, then logistical difficulties are an insufficient reason for not pursuing adequate protections for those affected. In recent years considerable scholarship has shown that development-induced displacement has produced an arguably far greater number of "oustees" than conflict-yet the millions forcibly removed by the building of dams, roads, and parks (amongst many other projects) find themselves left out of the conversation regarding refugee protections. ${ }^{23}$ A key challenge is the fact that displacement due to development is generally justified along nationalist or economic lines in a way that is for the most part unacceptable (other than to the most jingoistic of partisans) for conflict situations. ${ }^{24}$ Many of those who have found their lives irrevocably changed by development projects and schemes have little recourse, told that their sacrifice is for the greater common good. Displacement due to development projects also illustrates the inability of the current refugee system to address the challenge-repatriation to lands now submerged by a reservoir, for example, is clearly not an option.

A similar set of issues emerges when one considers environmentally induced displacement. The landscape or land-base may be irrevocably altered by a number of different environmental factors, rendering them uninhabitable-as farmlands parched by desertification or islands swallowed by rising waters attest to. The populations of such regions have little to no chance of returning-yet they experience scant luck in being deemed legitimate refugees. Perhaps more so than with development, the issue of causality becomes even more complicated and challenging in environmental displacement: who is to blame for the hazard posed to the Maldives, Tuvalu, or the deltas of Bangladesh? The nascent climate justice movement would certainly point to the overly consumptive and waste-producing economies and lifestyles of the industrial world as a culprit, and one might similarly point a finger at extractive industries and conservation initiatives for intensifying other forms of environmental displacement. However, these are all difficult to hold accountable for the impacts on a wide range of local communities.

Some critics-and certainly much of the political and public discourse-regarding environmental refugees have characterized them as little more than economic (or other) migrants who seek to use the trendy topic of climate change as a justification for making a move. ${ }^{25}$ While volition is often considered a key part of any definition of displacement-a coercive rather than a voluntary migration-the complicated manner in which environmental displacement occurs calls into question an easy distinction between the "choices" made to move. Displacement due to a "natural disaster" and its destruction of a landscape may seem straightforward, but what of those much longer-term processes (such as those engendered by certain types of climate change) that degrade an environment? How do the inhabitants of such lands-who may not be forced to flee by a cataclysmic and spectacular event, but by a slow and inexorable weakening of their socio-economic capacities-justify their need for sanctuary? How do communities who have adapted to certain forms of cyclical environmental hazardseasonal flooding, for example-by migrating to nearby regions temporarily make the argument that their risk has grown beyond their capability to manage it as the result of a changing climate? As White points out, the question of voluntariness in migration is seen as key in such situations as to whether nation states, international agencies, and the 
general public believe "relief or refugee status should be accorded to the person in flight." 26 The question of volition and coercion also reminds us that the distinctions between environmentally induced, conflict-induced, and development-induced displacement are rarely discrete; rather, they describe processes (and often justifications) that overlap, reinforce, and often stimulate one another, as the contributions to this special issue illustrate.

\section{Environmentally Induced Displacement: Contributions of the Special Edition}

We begin with three papers that explore the ways in which environmental displacement is conceptualized, negotiated, and governed at multiple scales. In a timely and insightful article, McAdam addresses the shifting and evolving landscape of recent international negotiations meant to establish a framework for addressing climate change, migration, and natural disasters. She traces the path from the Cancún Adaptation Framework of 2010 through the efforts of the UNHCR to develop a guiding framework on environmental displacement in 2011 to the creation of the Nansen Initiative designed to create policy-making on environment and displacement in 2012. Meyer complicates this same policy-making realm in terms of a number of competing perspectives and interests and argues that these produce the governance of environmental migration at multiple levels. He suggests in particular that a number of distinct normative frameworks are employed in pursuit of divergent goals, with the most successful being that of international security. In their critical contribution, Omezeri and Gore focus not on stakeholders more broadly or the international arena but rather on one specific state's approach to the question of environmental migration. Their examination of the Canadian government's policy in this regard suggests that it has relied upon ad hoc, temporary measures to address environmental refugee claims and is delaying the development of any more long-term policies until an international consensus (or at least standard) emerges. Canada is hence not likely, these authors contend, to become a policy leader in this regard.

Drolet, Sampson, Jebaraj, and Richard move our focus away from states and international agencies to the role of the NGOs, social service providers, and community advocates who must deal on a regular basis with the impacts of environmentally induced displacement. They provocatively examine how social work through its professional associations might help to address the challenges of environmental migration. In particular they highlight an international initiative called the Global Agenda aimed at recognizing and intervening in conditions of inequality and unsustainable practices across the world. Using a social justice framework, they argue that there is both a place for social work practitioners in protecting the rights of the displaced and a need to build greater understanding amongst social workers of the complex social, economic, and ecological connections implicit in environmental displacement.

What of the displaced themselves, who must live within the restrictions imposed by environmental displacement or alternatively evicted by such processes-not in theory or the future but in the present? In Blitz's article on the riverine and coastal-delta populations in Bangladesh, he uses the Sustainable Livelihoods framework to explore the relationships between place, and environmental and human security. He suggests that while the location is a vulnerable one-indeed, the situation of char-dwellers in an iconic illustration of the threats of climate change-a variety of adaptation responses by residents (including flexible migration and coping strategies) help residents to reduce their vulnerabilities. Blitz's article thus helps to complicate the ideas of environmental risks, hazards, and displacement itself. Thompson, Ballard, and Martin also focus on those who have been already affected by environmental displacement and add the important dimension of a focus on indigenous populations-often those who bear the brunt of environmental displacements-as they draw on interviews with members of the Lake St. Martin First Nation in the Canadian province of Manitoba, who describe their dislocation from their former homes. Their displacement was caused by a natural disaster and was equally an intentional act on the part of the provincial government who diverted the rising waters of a flood away from urban private property and sacrificed an indigenous community in the process. Also using the sustainable livelihoods framework, the authors suggest that the socio-economic vulnerabilities of community members have been increased as a result of this environmental disaster and associated displacement. Bringing the key question of power inequities to the fore, the authors, moreover, contend that a combination of racism, and lack of participation and power has rendered the situation ongoing and unresolved.

The final paper in our collection turns our attention away from institutional frameworks, social service associations, and environmental migrants and towards the displacers themselves. In an important theoretical addition and again one that foregrounds the issue of power, Butler uses postcolonial and critical race theory to examine the attitudes and perspectives of key figures within a "walled mine" in Northern Tanzania to provide important insights into the role of "the displacer" as a neo-liberal subject operating within a contemporary zone of neo-colonialist power relations. She argues that the psychological justifications used by such individuals and groups are central in understanding 
the structural violence experienced by those displaced by these types of extractive industries.

Taken together, these articles ask us to challenge and reconsider the ways in which we might understand environmental displacement, the processes that produce it, and the rationales that justify (or alternatively contest) it, and they suggest that further research on this burgeoning field is necessary to make the needed theoretical and practical interventions for alleviating this contemporary crisis.

\section{Notes}

1. Norman Myers, "Environmental Refugees," Population and Environment: A Journal of Interdisciplinary Studies 19, no. 2 (1999): 167-82; Olli Brown, Migration and Climate Change (Geneva: International Organization for Migration, 2008); Gregory White, Climate Change and Migration (Oxford: Oxford University Press, 2011).

2. Annelies Zoomers, "Globalisation and the Foreignisation of Space: Seven Processes Driving the Current Global Land Grab," Journal of Peasant Studies 37, no. 2 (2010): 429-47.

3. Mark Dowie, Conservation Refugees: The Hundred Year Conflict between Global Conservation and Native Peoples (Cambridge: MIT Press, 2009); Elizabeth Lunstrum, "Reconstructing History, Grounding Claims to Space: History, Memory, and Displacement in the Great Limpopo Transfrontier Park," South African Geographical Journal 92 no. 2 (2010): 129-43.

4. Peter Vandergeest, Pablo Idahosa, and Pablo S. Bose, eds., Development's Displacements: Economies, Ecologies and Cultures at Risk (Vancouver: UBC Press, 2007).

5. Anthony Oliver-Smith, Defying Displacement: Grassroots Resistance and the Critique of Development (Austin: University of Texas Press, 2010).

6. Koko Warner, "Global Environmental Change and Migration: Governance Challenges," Global Environmental Change 20, no. 3 (2010): 402-13; Richard Black, Neil Adger, Nigel Arnell, Stefan Dercon, Andrew Geddes, and David Thomas, "The Effect of Environmental Change on Human Migration," Global Environmental Change 21 (2011): S3-S11.

7. Francois Gemenne, "How They Became the Human Face of Climate Change: Research and Policy Interactions in the Birth of the 'Environmental Migration' Concept," in Migration and Climate Change, eds E. Piguet, A. Pécoud, and P. de Guchteneire, 225-60 (Cambridge: Cambridge University Press, 2011).

8. Norman Myers, "Environmental Refugees," Population and Environment: A Journal of Interdisciplinary Studies 19 no. 2 (1999): 167.

9. Michael Barnett, "Humanitarianism with a Sovereign Face: UNHCR in the Global Undertow," International Migration Review 35, no. 1 (2001): 244-77.
10. Olli Brown, Migration and Climate Change (Geneva: International Organization for Migration, 2008); Khalid Koser, "Changing Agendas in the Study of Forced Migration: A Report on the Fifth International Research and Advisory Panel Meeting, April 1996," Journal of Refugee Studies 9, no. 4 (1996): 53-66; Richard Black, "Environmental Refugees: Myth or Reality?" New Issues in Refugee Research Working No. 34 (Sussex: Centre for Development and Environment, University of Sussex, 2001), 1-20.

11. Essam El-Hinawi, Environmental Refugees (Nairobi: UNEP, 1985): 4.

12. Astri Suhrke and Annemarie Visentin, "The Environmental Refugee: A New Approach," Ecodecision, September 1991, 73.

13. Anthony Richmond, "Reactive Migration: Sociological Perspectives on Refugee Movements," Journal of Refugee Studies 6, no. 1 (1993): 7-24.

14. JoAnn McGregor, "Refugees and the Environment," in Geography of Refugees: Patterns and Processes of Change, ed. R. Black and V. Robinson, 157-71 (London: Bellhaven, 1993).

15. UNHCR, "Climate Change, Natural Disasters and Human Displacement: A UNHCR Perspective," in Climate Change and Displacement Reader, ed. S. Leckie, E. Simperingham, and J. Bakker (New York: Earthscan, 2012), 149.

16. Timo Koivurova, "International Legal Avenues to Address the Plight of Victims of Climate Change: Problems and Prospects," Journal of Environmental Law and Litigation 22 (2007): 267.

17. Karen Elizabeth McNamara and Chris Gibson, "We Do Not Want to Leave Our Land': Pacific Ambassadors at the United Nations Resist the Category of 'Climate Refugees," Geoforum 40, no. 3 (2009): 475-83.

18. Scott Leckie, Ezekiel Simperingham, Jordan Bakker,eds., Climate Change and Displacement Reader (New York: Earthscan, 2012).

19. Phillippe le Billon, "Geographies of War: Perspectives on 'Resource Wars," Geography Compass 1, no. 2 (2007): 163-82.

20. Michael Cernea, "The Risks and Reconstruction Model for Resettling Displaced Populations." World Development 25, no. 10 (1997): 1569-87.

21. Gil Loescher, Alexander Betts, and James Milner, The United Nations High Commissioner for Refugees (UNHCR): The Politics and Practice of Refugee Protection into the 21st Century (London: Routledge, 2008).

22. UNHCR, Guiding Principles on Internal Displacement (New York: United Nations, 2004).

23. Bogumil Terminski, "Development-Induced Displacement and Resettlement: Theoretical Frameworks and Current Challenges," Development 10 (2013): 101.

24. Peter Penz, Jay Drydyk, and Pablo S. Bose, Displaced by Development: Ethics, Rights and Responsibilities (Cambridge: Cambridge University Press, 2011). 
25. Maria Stavropoulou, "Drowned in Definitions," Forced Migration Review 31 (2008): 11-12.

26. Gregory White, Climate Change and Migration (Oxford: Oxford University Press, 2011), 26.

Pablo Bose is assistant professor of geography, Department of Geography, University of Vermont. The author may be reached at pbose@uvm.edu.

Elizabeth Lunstrum is associate professor of geography, Department of Geography, York University. author(s) are credited and the original publication in Refuge: Canada's Journal on Refugees is cited. 